\title{
SENTIDOS SILENCIADOS EM MATERIAIS DIDÁTICOS DE LÍNGUA INGLESA
}

\author{
SENTIDOS SILENCIADOS EN MATERIALES DIDÁCTICOS DE LENGUA INGLESA
}

SILENCED SENSES IN DIDACTIC MATERIALS OF ENGLISH LANGUAGE

Joelma Aparecida BRESSANIN ${ }^{1}$

Simone Miller da Silva CAMPOS ${ }^{2}$

RESUMO: Neste estudo objetivamos compreender como os materiais didáticos, destinados ao ensino da língua inglesa, levam em consideração a relação entre língua, sujeito e história (ideologia) e em que medida a prática de linguagem se configura nesses materiais. A pesquisa se inscreve na Análise de Discurso de linha francesa, fundada por Pêcheux e desenvolvida por Orlandi e outros pesquisadores, no Brasil. Dentre os recortes coletados, observamos que as culturas dos países de língua inglesa não são abordadas de maneira satisfatória, pois, muitas vezes, enfatiza-se apenas a cultura dos países hegemônicos, como Estados Unidos e Inglaterra, contribuindo para o trabalho de homogeneização linguística e visando uma ação mercadológica dos produtos euro-americanos. Portanto, é importante refletir a respeito dos sentidos silenciados, mas que estão em funcionamento no processo discursivo.

PALAVRAS-CHAVE: Ensino de línguas. Discurso. Silenciamento.

RESUMEN: En este estudio pretendemos comprender cómo los materiales didácticos, destinados a la enseñanza de la lengua inglesa, toman en consideración la relación entre lengua, sujeto e historia (ideología) y en qué medida la práctica del lenguaje se configura en esos materiales. La investigación se inscribe en el Análisis de Discurso de línea francesa, fundada por Pêcheux y desarrollada por Orlandi y otros investigadores, en Brasil. Entre los recortes recogidos, observamos que las culturas de los países de habla inglesa no se abordan de manera satisfactoria, pues a menudo se enfatiza sólo la cultura de los países hegemónicos, como Estados Unidos e Inglaterra, contribuyendo al trabajo de homogeneización lingüística y con vistas a una acción mercadológica de los productos euroamericanos. Por lo tanto, es importante reflexionar acerca de los sentidos silenciados, pero que están en funcionamiento en el proceso discursivo.

PALABRAS CLAVE: Enseñanza de idiomas. Discurso. Silenciamiento.

ABSTRACT: In this study we aimed to understand how didactic materials, destined to the teaching of the English language, take into account the relation between language, subject

\footnotetext{
${ }^{1}$ Universidade do Estado de Mato Grosso (UNEMAT), Cáceres - MT - Brasil. Professora Doutora do Curso de Pós-Graduação em Linguística da Unemat. ORCID: <http://orcid.org/0000-0002-5684-4961>. E-mail: joelmaab@hotmail.com

${ }^{2}$ Universidade do Estado de Mato Grosso (UNEMAT), Cáceres - MT - Brasil. Pós-graduanda do Curso de Doutorado em Linguística da UNEMAT. ORCID: <http://orcid.org/0000-0003-4694-507X>. E-mail: simonemiller5@hotmail.com
} 
and history (ideology) and to what extent language practice is configured in these materials. The research is inscribed in French Speech Analysis, founded by Pêcheux and developed by Orlandi and other researchers, in Brazil. Among the collected data, we observed that the cultures of the English language countries are not satisfactorily addressed, because, many times, it is emphasized only the culture of the hegemonic countries, such as the United States and England, contributing to the work of linguistic homogenization and aiming at a marketing action of Euro-American products. Therefore, it is important to reflect on the silenced senses, but that are functioning in the discursive process.

KEYWORDS: Language teaching. Speech. Silencing.

\section{Introdução}

A crescente globalização e a necessidade de uma linguagem eficiente de comunicação fazem com que a língua inglesa seja vista atualmente como fundamental em todo o mundo. Concebida como língua internacional, muitos a denominam como a língua dos negócios, viagens, cultura, tecnologia etc. Sendo assim, tornou-se a língua da comunicação mundial. E, nesse contexto, essa posição hegemônica do inglês como língua estrangeira (LE) contribuiu para a criação de vários cursos de inglês e, consequentemente, vários materiais didáticos para atender às necessidades de seus aprendizes. No Brasil, atualmente, é a LE obrigatória no sistema de ensino regular. Assim, para esta pesquisa, selecionamos materiais didáticos, especificamente algumas apostilas de língua inglesa, pertencentes a dois sistemas de ensino adotados por muitas escolas privadas ${ }^{3}$, que apresentam textos e imagens que proporcionam indagações nos limites da ideologia, do poder, da classe, da raça e do gênero, produzindo um discurso que silencia outros sentidos. Conforme Cavallari e Araújo (2016), o livro didático, seja pelo investimento das editoras, seja pelas representações imaginárias de conteúdos inquestionáveis, no caso, o material didático de inglês assume a condição de legitimador do saber. Então, é importante ressaltar que, de acordo com Coracini (2011 apud CAVALLARI; ARAÚJO, 2016, p. 110):

O conteúdo veiculado no/pelo LD deixa de ser problematizado, o que favorece o embotamento da percepção do leitor em relação aos possíveis posicionamentos ideológicos contidos no material adotado, sem que os

${ }^{3}$ Convém ressaltar que não identificamos os nomes dos sistemas de ensino, pois entendemos que o enfoque que buscamos dar é para o funcionamento da linguagem, que de modo semelhante a outros materiais didáticos de língua inglesa, se constitui a partir de um imaginário de língua já dado. E, no decorrer do artigo, nos referimos a materiais didáticos de língua inglesa e não apostilas, embora estes também sejam conhecidos por método apostilado. 
agentes educacionais percebam a incidência dos aspectos culturais e ideológicos no processo de ensino-aprendizagem.

Pelo viés da perspectiva discursiva, compreende-se que os materiais didáticos produzem sentidos sobre a língua, levando em consideração sua relação com as outras línguas e, portanto, com as práticas sociais, culturais, ideológicas relativas aos falantes, especialmente, quando estes buscam apreendê-la enquanto segunda língua.

Dessa forma, esta pesquisa propõe desenvolver um estudo discursivo sobre materiais didáticos apostilados de Língua Inglesa, observando o funcionamento dos processos de significação de discursos ditos e/ou silenciados, por meio de atividades que são propostas neles, relativas à cultura de países hegemônicos como Estados Unidos e Inglaterra.

A pesquisa está ancorada no dispositivo teórico-metodológico da Análise de Discurso de linha francesa, fundada por Pêcheux e desenvolvida por Orlandi e outros pesquisadores, no Brasil. Para o trabalho, serão mobilizados os conceitos de discurso, ideologia, sujeito, formação discursiva, formação ideológica, formação imaginária e memória discursiva.

A disciplina teórica nos possibilita observar o movimento dos sentidos produzidos no material analisado. Sendo que um conceito fundamental para tal análise é o de memória discursiva (ORLANDI, 2015). Uma vez que pensamos a língua como uma materialidade sempre sujeita a falhas e a equivocidade, assim, é na relação entre língua-discurso-ideologia que buscamos compreender como os sentidos, bem como seus efeitos são produzidos na história.

\section{Conceitos norteadores desta pesquisa}

A palavra discurso, etimologicamente falando, alude a processo, percurso, movimento. $\mathrm{O}$ discurso é definido como efeito de sentido entre interlocutores e refere-se à linguagem em movimento (ORLANDI, 2015). Não há discurso sem sujeito. É por isso que a $\mathrm{AD}$ não trabalha com a língua como um sistema abstrato, mas com maneiras de significar, com homens falando:

Portanto, o sujeito e a situação que tinham sido postos para fora da análise linguística, contam fundamentalmente para a análise de discurso. Mas este sujeito e esta situação contam na medida em que são redefinidos discursivamente como partes das condições de produção do discurso. Daí dizemos que na análise de discurso não podemos deixar de relacionar o discurso com suas condições de produção, sua exterioridade (ORLANDI, 2015. p. 17). 
Com efeito, o discurso tem relação com sua exterioridade, sendo esta ideológica e/ou histórica, considerando sempre suas condições de produção, assim, faz-se necessário que o analista leve em consideração que há uma relação fundamental do discurso e da linguagem com sua exterioridade.

Compreende-se que o material didático apostilado de língua inglesa é uma prática significante, a qual é afetada pela história e pela ideologia para produzir efeitos de sentido. Observa-se que, "não é neutro e não está livre de determinações ideológicas, já que os sujeitos que elaboram os materiais, assim como os professores, são afetados pela língua e pela história" (FURLAN; MEGID, 2009, p. 12). Nota-se que, os discursos desses materiais, impregnados de historicidade — que é ideologia —, a todo instante depara-se com o já dito, que é o discurso reproduzido de que os Estados Unidos são uma potência econômica mundial e a língua inglesa é a língua franca, global. A esse respeito, Orlandi (2015, p. 24) apresenta o conceito de memória discursiva que "é trabalhada pela noção de interdiscurso: 'algo que fala antes, em outro lugar e independentemente'. Trata-se do que chamamos saber discursivo. É o já dito que constitui todo o dizer".

E, muitas vezes, há também o não dito, um silenciamento que produz efeitos de sentidos por meio da articulação entre as formulações verbais e não-verbais dos materiais didáticos de língua inglesa. E esse silêncio, para Orlandi (2007), não é mero complemento da linguagem, ele tem significância própria, há um sentido no silêncio. Então, conforme Orlandi (2007, p. 12), na perspectiva discursiva,

todo dizer é uma relação fundamental com o não-dizer. Essa dimensão nos leva a apreciar a errância dos sentidos (a sua migração), a vontade do "um" (da unidade, do sentido fixo), o lugar do non sense, o equívoco a incompletude (lugar dos muitos sentidos, do fugaz, do não-apreensível), não como meros acidentes da linguagem, mas como o cerne mesmo de seu funcionamento.

E, esses discursos, silenciados ou não, envolvendo países como Estados Unidos ou Inglaterra são tomados pelas formações ideológicas que estão em jogo no processo discursivo. A respeito das formações ideológicas, Pêcheux (2014, p. 132) expõe que:

[...] a instância ideológica existe sob a forma de formações ideológicas (referidas aos aparelhos ideológicos de Estado), que, ao mesmo tempo, possuem caráter 'regional' e comportam posições de classe: os 'objetos' ideológicos são sempre fornecidos ao mesmo tempo que a 'maneira de se servir deles' - 'seu sentido', isto é, sua orientação, ou seja, os interesses de classe aos quais eles servem -, o que se pode comentar dizendo que as ideologias práticas são práticas de classes (de lutas de classes) na Ideologia. 
Não há sujeito, discurso ou linguagem sem ideologia. É a ideologia que determina os sentidos, e o processo interpretativo se concretiza através da ideologia, nas condições históricas em que o sujeito está inserido: "não podemos pensar o sujeito como origem de si. Aí estabelece o teatro da consciência segundo o qual o indivíduo é interpelado em sujeito pela ideologia, pelo simbólico. Dessa interpelação do indivíduo em sujeito resulta uma formasujeito histórica" (ORLANDI, 2015, p. 21).

Sendo assim, os autores de livros didáticos têm a ilusão de que são a fonte de seus dizeres e sentidos. Mas isso não acontece, pois estes apenas reproduzem outros dizeres constituídos na história, sendo que "toda e qualquer sequência discursiva por eles [autores] produzida pertence a uma formação discursiva que, por sua vez, tem relação com uma determinada formação ideológica" (FURLAN; MEGID, 2009, p. 12-13).

Não podemos separar língua, ideologia e história, pois "o discurso é a materialidade específica da ideologia e a língua e a materialidade específica do discurso. Desse modo temos a relação entre língua e ideologia afetando a constituição do sujeito e do sentido" (ORLANDI, 2015, p. 20).

Dessa forma, vivemos em um momento histórico em que a aprendizagem da língua inglesa é vista como de fundamental importância no mundo globalizado, seja para o meio educacional ou para o meio profissional, sendo importante que os professores conheçam mais a respeito das questões políticas e ideológicas que implicam a aprendizagem dessa língua.

Diante desse contexto de globalização, observamos nos materiais didáticos apostilados de língua inglesa um discurso capitalista, com um imaginário de língua padrão, sendo que esse inglês padrão seria a língua falada em países, que representam "prestígio" e "riqueza", como Estados Unidos e Inglaterra. A esse respeito, Furlan e Biazotto (2008, p. 44) argumentam que:

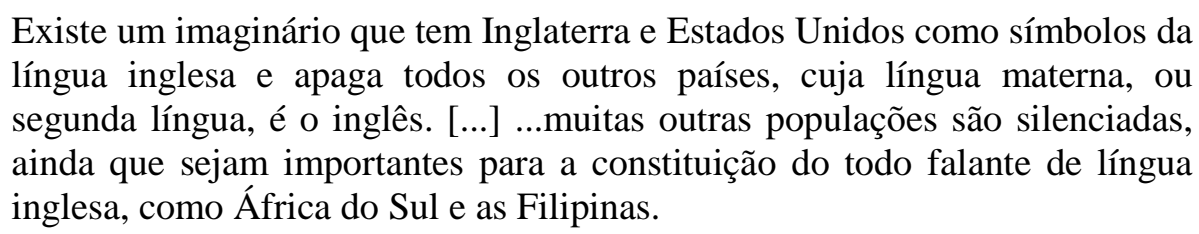

Sendo assim, quando partimos desse imaginário de língua inglesa padrão, referente unicamente a países como Estados Unidos e Inglaterra, somos interpelados por uma ideologia dominante constituída na história por relações de poder. Quando reproduzimos esse discurso, é como se colocássemos esses dois países como superiores, como modelos a serem seguidos 
tendo em vista que a língua inglesa representa a língua do comércio, da cultura, da tecnologia, da ciência etc. (PENNYCOOK, 1994 apud FURLAN; BIAZOTTO, 2008).

Com base nos conceitos e considerações apresentadas, daremos início à análise de alguns recortes dos materiais selecionados.

\section{O dito e o não dito nos materiais didáticos analisados}

$\mathrm{Na}$ análise, como já foi dito, optamos por não revelar quais materiais didáticos apostilados foram utilizados, apresentando recortes deles. Este trabalho não terá como objetivo abordar a metodologia, a estrutura gramatical ou expor a empresa que produziu o material, mas sim proporcionar uma reflexão a respeito dos discursos que estão ditos e dos que estão silenciados, propondo assim, aos professores e alunos, um olhar mais atento ao funcionamento da linguagem, bem como da prática que se desenvolve no ensino de línguas.

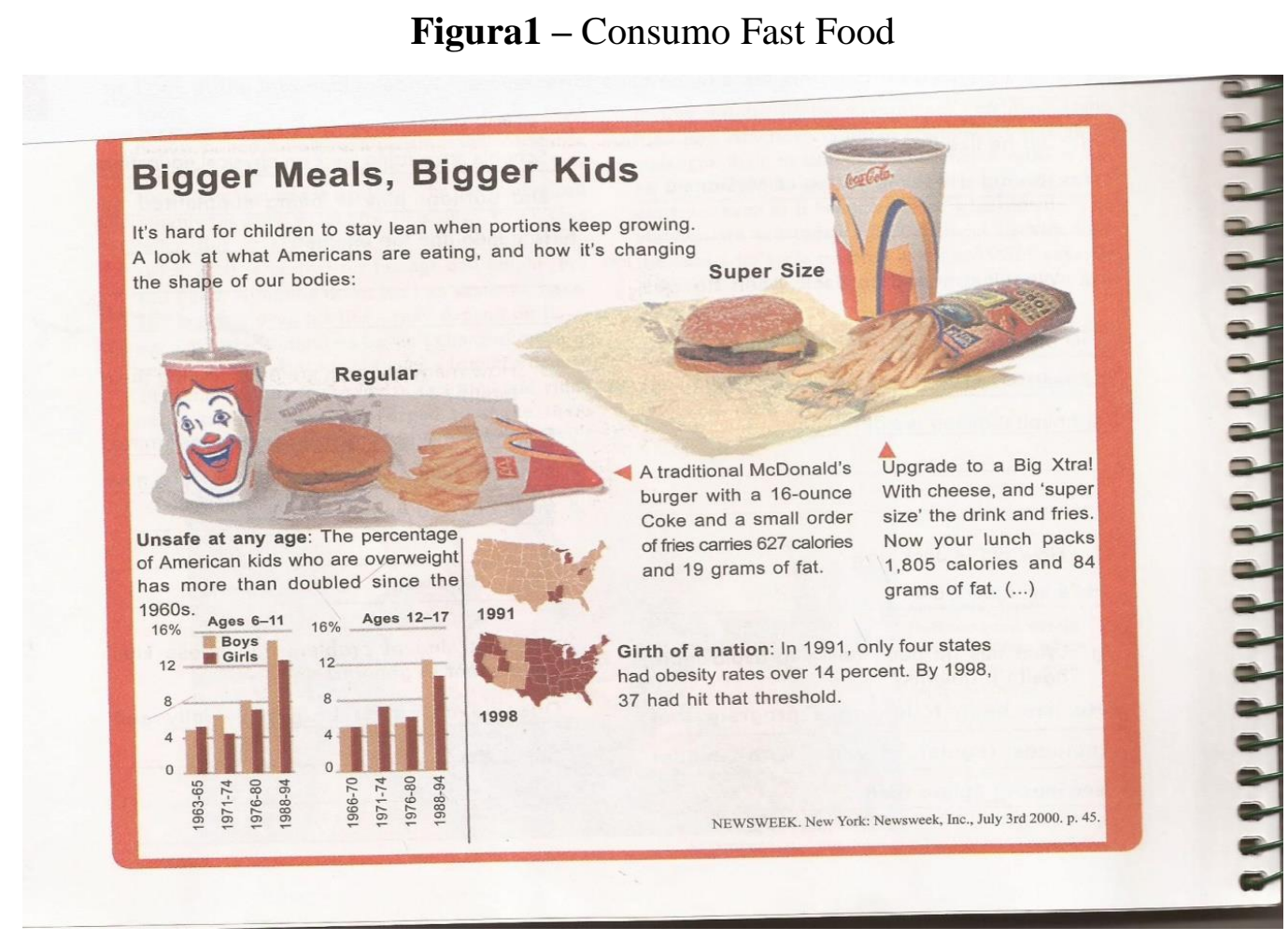

Fonte: Newsweek (2000)

No recorte 1 observamos que são apresentadas informações referentes ao consumo de fast food e o crescimento da obesidade entre as crianças. Para esse propósito, poderia ter sido selecionado apenas uma imagem de um lanche, batata e refrigerante, mas optaram por colocar 
uma imagem voltada à marca do McDonald, empresa norte-americana que representa uma das maiores cadeias mundiais de fast food de hambúrguer. Dessa forma, podemos observar que, ao apresentar a empresa McDonald's, há um dito que busca (re)produzir um efeito de familiaridade do aluno com tal marca e, também, um não dito produzindo sentidos ao se mencionar nomes de grandes empresas multinacionais, ou seja, vemos que o discurso da propaganda imbrica-se no discurso didático e dá a entender que, para ter o domínio da língua inglesa, o aluno também deve conhecer os produtos consumidos nos países onde se pratica essa língua. Outra situação observada é a respeito da contradição presente no discurso do recorte, pois ao mesmo tempo em que traz informações sobre o crescimento da obesidade, atua na divulgação do produto.

Conforme Kumaravadivelu (2006, p. 132), o teórico político Barber (1996) e o sociólogo Ritzer (1993):

acreditam que algum tipo de homogeneização cultural está ocorrendo e que, nela, a cultura norte-americana de consumo constitui o centro dominante. Veem uma equação simples e direta: globalização $=$ ocidentalização $=$ norteamericanização = mcdonaldização. [...] O termo 'mcdonaldização' foi criado pelo sociólogo Ritzer (1993) para descrever os processos socioculturais pelos quais os princípios básicos da comida rápida - a criação de produtos de consumo homogeneizado e a imposição de padrões uniformes - dão forma à paisagem cultural dos Estados Unidos e de outras partes do mundo.

Orlandi (2009, p. 222) compreende esse processo, pelo viés discursivo, como efeito da "mundialização":

O discurso sobre o mundo globalizado se acompanha de mistificações, de previsões fantasiosas, o que vai constituindo um imaginário sobre a mundialização que torna mais difícil compreender os seus sentidos.

A mundialização, segundo Laurent Carroué (2005), é um processo geohistórico de extensão progressiva do capitalismo em escala planetária e que é ao mesmo tempo uma ideologia (O liberalismo), uma moeda (o dólar), um instrumento (o capitalismo), um sistema político (a democracia), uma língua (o inglês).

Para a autora, essa mundialização reforça as desigualdades, tanto no plano espacial como no plano social. Então, esses materiais didáticos produzem situações de comunicação que "não poderiam se endereçar a alunos das classes brasileiras sócio economicamente desfavorecidas, que [...] em nenhum momento, se acham representados" (CORACINI, 2016, p. 46-47). No entanto, esse contexto poderia contribuir para duas situações: o aluno receberia isso como estímulo e buscaria se esforçar para ter melhor qualidade de vida ou, simplesmente, 
se sentiria mais desmotivado pensando que nunca conseguiria alcançar o que foi exposto por esses materiais.

Nesse sentido, passaremos, então, ao recorte 2.

Figura 2 - Referência deaprendizagem

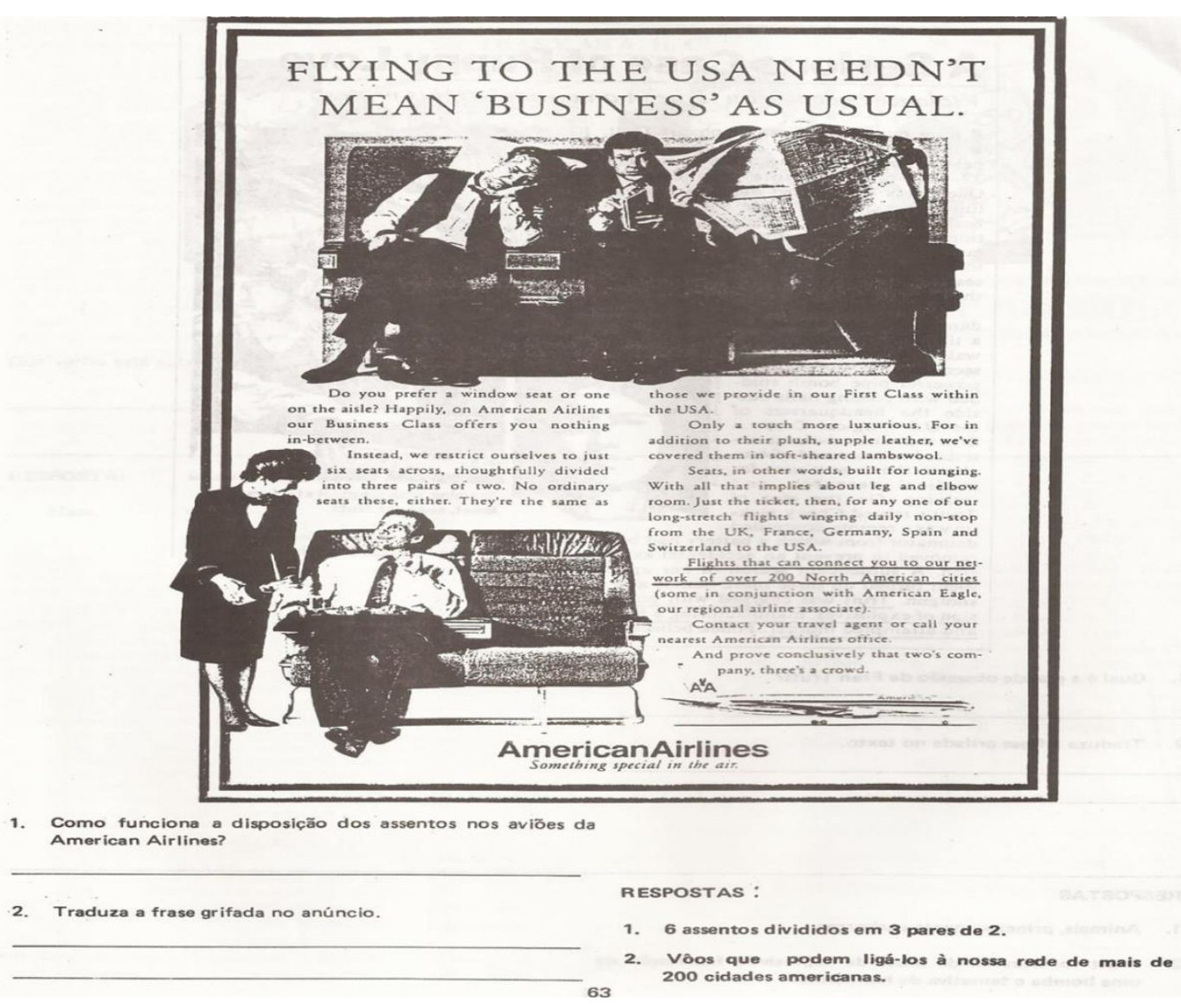

Fonte: Wikipédia - Recorte material didático - autoras

Nessa proposta apresentada pelo material didático (recorte 2), observamos, novamente, que o cenário criado para a situação de aprendizagem da língua faz referência a uma grande empresa, a AmericanAirlines ${ }^{4}$, "uma companhia aérea americana sediada em Fort Worth, Texas. É a maior companhia aérea do mundo por passageiros transportados, quantidade de aeronaves e receitas, sendo a segunda maior pelo número de destinos, somente atrás da United Airlines". Vemos, então, uma empresa norte-americana e o abismo que é criado entre ricos e pobres por meio dessa mundialização, sendo que, dificilmente, uma pessoa menos favorecida terá condições de voar com o conforto apresentado pela companhia.

${ }^{4}$ Informação disponível em: <https://pt.wikipedia.org/wiki/American_Airlines>. 
Na imagem, por exemplo, é possível ver duas situações contrastantes entre os passageiros que optam ou não pela empresa.

Nota-se que, nesses recortes (1 e 2), está em funcionamento um discurso da questão mercadológica da língua inglesa, que atualmente representa a língua do comércio, da tecnologia e da cultura. Conforme Celada e Payer (2016), temos que reconhecer que o entrelaçamento entre Estado e Mercado, próprio das políticas neoliberais da atual fase do capitalismo, afeta o modo como a língua e as línguas são projetadas. Constrói-se, então, uma representação de que ao dominar essa língua, o sujeito teria privilégios. Dessa forma, esse sujeito acaba reproduzindo posições ideológicas norte-americanas, consumindo o lanche, viajando naquela empresa aérea, sentindo-se, assim, aceito na sociedade capitalista.

Sendo assim, ressaltamos que não se pode separar a língua de questões de saber, poder e ideologia, pois para Orlandi $(2015$, p. 16) “ao deslocar, não dicotomizando, para a relação língua e discurso, o discurso desta vez é sujeito à análise de seu funcionamento, contanto que atentemos para a relação do que é linguístico com a exterioridade que o determina. No discurso temos o social e o histórico indissociados".

Apresentamos abaixo o recorte 3 para observarmos o modo como o texto significa a partir da relação entre o verbal e o visual.

Figura 3 - Recortes material didático

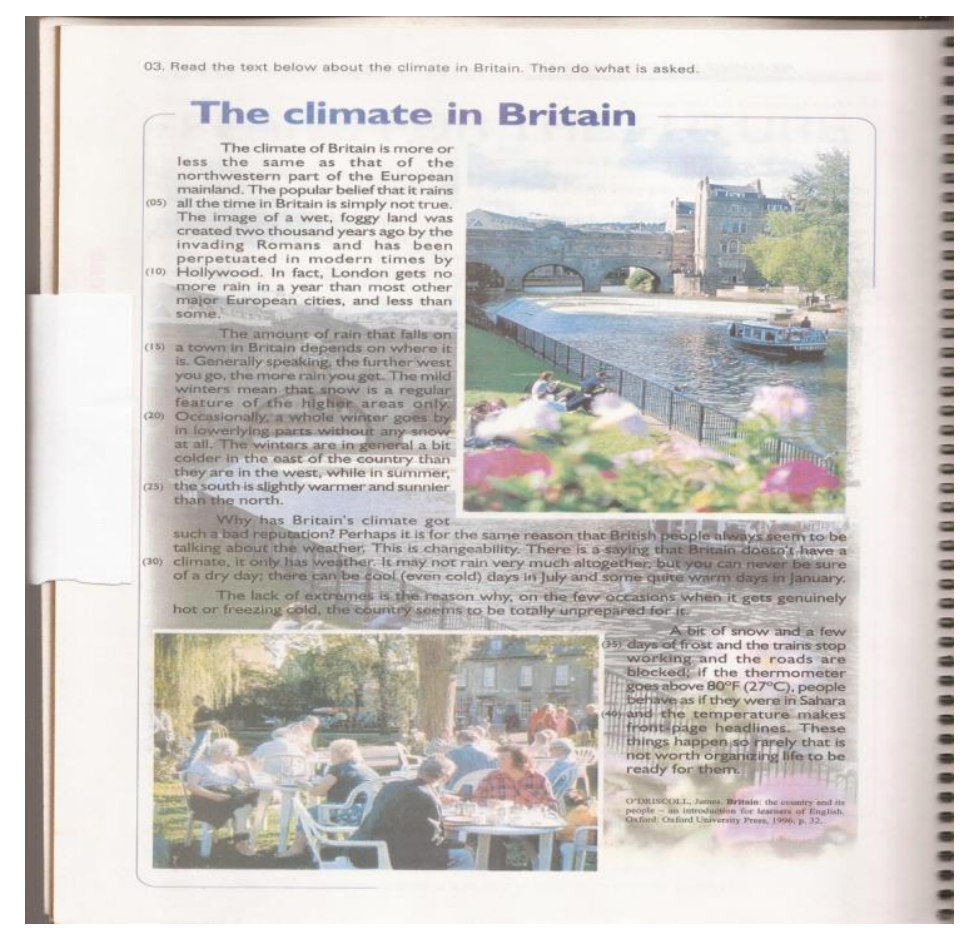




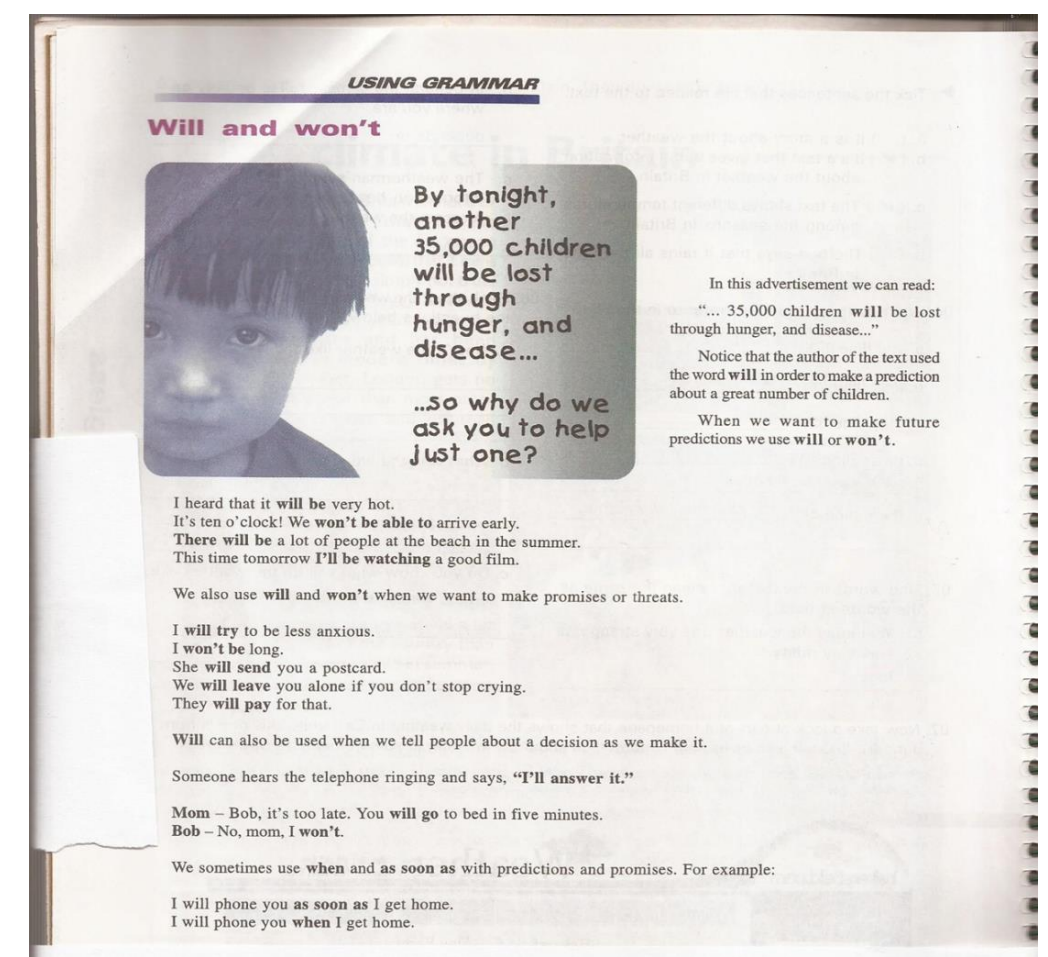

Fonte: Acervo autoras

Notamos que no primeiro texto da unidade 1, o assunto abordado é o clima na GrãBretanha, descrito como semelhante ao da parte noroeste do continente europeu. Relata-se a respeito da chuva, que não é tão recorrente e que a neve é regular em áreas mais altas apenas. Logo após, informam que os invernos são um pouco mais frios no leste que no oeste do país, enquanto que, no verão, o sul é levemente mais quente e ensolarado que no norte. Então, há um questionamento a respeito da má reputação do clima da Grã-Bretanha, que é apresentado como mutável e não definido. Diante de tal situação, as pessoas nunca estão preparadas. Acompanham a linguagem verbal, duas imagens de belezas naturais da Inglaterra, sendo ilustrado também o famoso chá da tarde inglês. Isso não causaria tamanha inquietação, se não fosse a outra imagem que segue, pois, diferentemente, não se trabalha o texto em si.

Trata-se da imagem de uma criança, acompanhada de enunciados que chamam a atenção para o fato de que há crianças morrendo de fome e doenças apenas como pretexto para explicar o uso de will e won't enquanto estrutura morfossintática da língua inglesa. Não se explicita a fonte consultada, nem há comentários a respeito da imagem, que pode ser entendida como uma mera ilustração. A nosso ver, no conjunto das situações abordadas nessa unidade de estudo, o não dito está significando, sobretudo, na imagem da criança de outra cultura, que não é a britânica, mas que sequer é identificada. Apaga-se, desse modo, outras culturas, outras línguas, pela sobreposição da língua inglesa. Essa atividade pode possibilitar 
uma oportunidade de problematização para o professor realizar em sala de aula, discutindo com os alunos não apenas os fenômenos linguísticos, mas os processos ideológicos que se articulam no discurso desses materiais e, também, o funcionamento do não dizer, pois os não ditos também significam (ORLANDI, 2007).

A respeito desse discurso da língua inglesa voltada unicamente a países hegemônicos como Estados Unidos e Inglaterra, Furlan e Biazotto (2008, p. 46) expõem que:

Quando falamos em Inglaterra e Estados Unidos, remetemos a um discurso de prestígio e riqueza e, principalmente, difundimos formas de cultura e conhecimento específicos e legitimados. Com isso, silenciamos todas as outras sociedades e, por sua vez, seus conhecimentos e suas culturas. Reduzimos, assim, os falantes de inglês a dois países e duas culturas. Nós silenciamos outros povos, outras culturas, outros saberes e, portanto, apagamos a chance de acesso ao novo.

Então, quando o professor trabalha com o aluno apenas o que é apresentado pelo material didático, ele acaba contribuindo para esse silêncio ou silenciamento, não permitindo que o educando tenha acesso ao novo. Diante disso, é interessante a distinção entre silêncio e silenciamento proposta por Coracini (2016, p. 48): "o silêncio é uma forma sutil de eliminar, de discriminar o outro, de marginalizar, de desprezar. O silêncio - não o silenciamento que é proposital e imposto pelo poder soberano - (re)vela aquilo que conscientemente não se quer admitir, mas que funciona como verdade do inconsciente". Ainda nesse mesmo caminho, conforme Cavallari e Araújo (2016, p. 115): “os sentidos podem ser 'administrados' por um corpo socialmente legitimado que produz poder-saber, tal como a escola e o livro didático, que constituem regimes de verdade que 'silenciam' certos sentidos para que outros possam emergir como "verdadeiros"”, ou seja, os sentidos produzidos pelos discursos dos materiais didáticos possuem efeito de verdade, o já dito retorna sob a forma do pré-construído, sustentando a supremacia da língua inglesa nesses materiais. E tudo isso repousa no funcionamento de uma memória discursiva, que é constituída nos/pelos materiais didáticos, sendo que, "todo dizer se acompanha de um dizer já dito e esquecido que o constitui em sua memória" (ORLANDI, 2015, p. 24). No entanto, outros dizeres são silenciados, apagando determinados discursos, camuflando as relações de poder-saber. Assim, conforme Foucault (1996, p. 12 apud CAVALLARI; ARAÚJO, 2016, p. 115):

Todo o sistema de educação é uma maneira política de manter ou de modificar a apropriação dos discursos, com os saberes e os poderes que estes trazem consigo. [...] O que é, no fim de contas, um sistema de ensino senão uma ritualização da fala, senão uma qualificação e uma fixação dos papéis dos sujeitos falantes; senão a constituição de um grupo doutrinal, por difuso 
que seja; senão uma distribuição e uma apropriação do discurso com os seus poderes e os saberes?

Esses questionamentos são muito importantes para esta análise, em que o silenciamento produzido nos/pelos materiais didáticos tem relações de poder-saber que estão presentes no ensino de língua inglesa. Retomamos também Orlandi (2015, p. 32), quando observa: "a análise de discurso trabalha com as relações de poder simbolizadas. Não há dizer que não seja político, no sentido em que o próprio processo de significação é dividido, depende de relações que derivam do contexto sócio-histórico". Nessa direção, a análise de discurso trabalha com sentidos ou sujeitos materialmente constituídos por suas relações com a sociedade e a história, sendo esse processo inerente ao aprendizado de línguas.

\section{Considerações finais}

Por meio da análise feita, podemos pontuar que há um silenciamento de outras línguas e de seus falantes, uma vez que uma dada cultura é apresentada como superior às demais. Esse silenciamento pode ora produzir efeito de verdade, ora direcionar os sentidos para uma dada interpretação, apagando outros sentidos possíveis. Sendo assim, é importante desconstruir determinados efeitos de verdade e sentidos já naturalizados, pois o que está posto por esses materiais pode contribuir para que o sujeito não só reproduza a língua, mas também as posições ideológicas euro-americanas. Dessa forma, há uma tentativa de apagamento de que a língua inglesa é atravessada por uma ideologia dominante, mas traz um discurso de que, esta por ser de todos - língua global - é neutra.

Convém destacar que não somos contrários ao uso dos materiais didáticos de língua inglesa no contexto escolar e/ou nos cursos para fins específicos. O que propomos é uma reflexão ao professor, ao aluno, bem como aos elaboradores desses materiais, a respeito dos sentidos silenciados ou não e, assim, chamar a atenção para que o conteúdo possa ser problematizado, com uma visão menos ingênua e mais atenta aos compromissos éticos e políticos em relação ao ensino de línguas.

\section{REFERÊNCIAS}

CAVALLARI, J. S.; ARAÚJO, A. M. S. de. As formas do silêncio em um material didático de inglês para militares. In.: CORACINI, M. J.; CAVALLARI, J. S. (Des)construindo 
verdade(s) no/pelo material didático: discurso, identidade, ensino. Campinas, SP: Pontes Editores, 2016.

CORACINI, M. J. Pobreza e marginalidade em livro didático de francês como língua estrangeira: entre o poder e a discriminação. In.: CORACINI, M. J.; CAVALLARI, J. S. (Des)construindo verdade(s) no/pelo material didático: discurso, identidade, ensino. Campinas, SP: Pontes Editores, 2016.

FURLAN, C. C.; BIAZOTTO, A. D. Inglês e o silenciamento dos povos. In: BOLOGNINI, C. Z. (Org.) Discurso e ensino: a língua inglesa na escola. Campinas, SP: Mercado de Letras, 2007.

FURLAN, C. C.; MEGID, C. Maria. Língua e linguagem em movimento na sala de aula. BOLOGNINI, C. Z.; PFEIFFER, C.; LAGAZZI, S. (Orgs.). Discurso e ensino: práticas de linguagem na escola. Campinas, SP: Mercado de Letras, 2009.

KUMARAVADIVELU, B. Linguística Aplicada na era da globalização. In: MOITA-LOPES, L. P. (Org.). Por uma linguística aplicada indisciplinar. São Paulo: Parábola Editorial, 2006.

ORLANDI, E. P. As formas do silêncio: no movimento dos sentidos. 6. ed. Campinas, SP: Editora da Unicamp, 2007.

ORLANDI, E. P. Espaço da violência: o sentido da delinquência. Caderno de estudos linguísticos. Campinas, SP: Unicamp, v. 51, v. 2, p. 219-234, jul./dez., 2009.

ORLANDI, E. P. Análise de discurso. In.: ORLANDI, E. P.; LAGAZZI-RODRIGUES, S. (Orgs.). Discurso e Textualidade. 3. ed. Campinas, SP: Pontes Editores, 2015.

PAYER, M. O.; CELADA, M. T. (Orgs.) Sobre sujeitos, língua(s), ensino, notas para uma agenda. In: PAYER, M. O.; CELADA, M. T. (Orgs.). Subjetivação e processos de identificação. Sujeito e línguas em práticas discursivas - inflexões no ensino. Campinas, SP: Pontes Editores, 2016.

PÊCHEUX, M. Semântica e discurso: uma crítica à afirmação do óbvio. Trad. de Eni P. Orlandi. et al. 4 ed. Campinas, SP: Editora da Unicamp, 2014.

\section{Como referenciar este artigo}

BRESSANIN, Joelma Aparecida.; CAMPOS, Simone Miller da Silva. Sentidos silenciados em materiais didáticos de língua inglesa. Rev. EntreLínguas, Araraquara, v. 4, n. 2, p. 268280, jul./dez., 2018. e-ISSN: 2447-3529. DOI: 10.29051/rel.unesp.v4.n2.2018.11612

Submetido em: 30/07/2018

Revisões requeridas em: 29/08/2018

Aprovação final em: 10/10/2018 